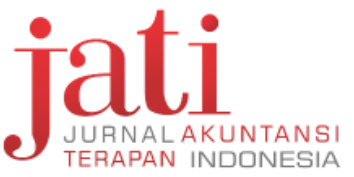

Jati: Jurnal Akuntansi Terapan Indonesia Vol 2 No 2 Hal 52-58 Oktober 2019

\title{
Analisis Penerapan Sistem Informasi Akuntansi Persediaan Obat Dalam Pencegahan Kecurangan Pada Puskesmas
}

\author{
http://journal.umy.ac.id/index.php/jati \\ DOI: 10.18196/jati.020218
}

DATA ARTIKEL:

Diterima: 26 Juli 2019

Direviu: 16 September 2019

Direvisi: 16 Oktober 2019

Disetujui: 31 Oktober 2019

TOPIK ARTIKEL:

Akuntansi Sektor Publik, Akuntansi Syariah

ABSTRAK: Penelitian ini bertujuan untuk menemukan: 1). Sistem informasi akuntansi di puskesmas. 2) pencegahan kecurangan di puskesmas. 3) peran sistem informasi akuntansi dalam pencegahan kecurangan. 4) kendala dalam menerapkan sistem informasi akuntansi. Variabel terdiri dari sistem informasi akuntansi dan pencegahan kecurangan. Metode yang digunakan dalam penelitian ini adalah metode kualitatif dengan pendekatan deskriptif. Penelitian ini dilakukan dengan observasi dan wawancara dengan pihak-pihak yang terlibat dalam penerapan sistem informasi akuntansi. Penerapan sistem informasi akuntansi telah diterapkan pada tiga dari empat pusat kesehatan yang telah diteliti. Walaupun keempat puskesmas memiliki kekurangan yang hampir sama dalam menerapkan sistem informasi akuntansi, yaitu kurangnya sumber daya manusia dan saran tentang infrastruktur yang mendukung implementasi sistem ini. Pencegahan kecurangan yang diterapkan pada setiap puskesmas sama yaitu dengan memberikan surat peringatan kepada karyawan yang melakukan kecurangan.

Kata Kunci: Sistem Informasi Akuntansi, Pencegahan Kecurangan, Kendala

ABSTRACT: This study to find out : 1). Accounting information system at the puskesmas. 2) prevention of fraud at the puskesmas. 3) the role of accounting information systems in fraud prevention. 4) contraints in implementing accounting information systems. The variable consits of an accounting information systems and fraud prevention. The method used in this study is a qualitative method with a descriptive approach. This research was conducted by observation and interviews with parties involved $i$ the application of accounting information systems. The application of accounting information systems has been applied to three of the four health centers that have been studied. Although the four puskesmas have the sam contraints in implementing accounting information systems, namely the lack of human resourcesan advice on infrastructure that supports the implementation of this systems. Fraud prevention applied to each puskemas is the same, namely by giving a warning letter to employees who commit fraud.

Keywords:Accounting Information Systems, Fraud Prevention, Contraints

\section{SITASI ARTIKEL:}

Nurhasanah, S., Ismatullah, I., \& Sofiani, V. (2019). Analisis Informasi Akuntansi Persediaan Obat Dalam Pencegahan Kecurangan Pada Puskesmas. Jati: Jurnal Akuntansi Terapan Indonesia, 2(2), 52-58.

\section{PENDAHULUAN}

Kecurangan atau fraud merupakan salah satu hal yang fenomenal baik di Negara maju maupun Negara berkembang. Kecurangan merupakan perilaku menyimpang dan perbuatan melanggar hukum yang dilakukan secara sengaja, untuk kepentingan pribadi atau kelompok secara langsung dan tidak langsung merugikan pihak atau orang lain. Dalam melaksankan kegiatan perusahaan, maka dimungkinkan terjadinya tindak kecurangan. Kecurangan merupakan tindakan yang disengaja yang dilakukan oleh satu orang atau lebih antara manajemen, karyawan atau pihak ketiga. Kecurangan juga dapat dilihat sebagai kekeliruan yang di sengaja, penyembunyian atas kebenaran yang disalah gunakan untuk tujuan penipuan atau memanipulasi yang merugikan pihak lain. 
Fraud atau kecurangan merupakan tindakan menyimpang dan melanggar hukum, karena keecurangan merupakan tindakan yang dapat merugikan orang/ pihak lain. Fraud terjadi karena alasan yaitu mengenai pengendalian internal yang lemah, pemahaman yang kurang terhadap aturan, dan monitoring yang kurang baik. Adapun sisi pendekatan pribadi menurut cressey yang disebut degan Fraud Triangle yaitu tekanan, kesempatan dan rasionalisasi.

Persediaan (inventory) merupakan aktiva perusahaan yang menempati posisi yang cukup penting dalam suatu perusahaan, baik itu perusahaan dagang maupun perusahaan manufaktur. Hampir sebagian dan perusahaan tertanam dalam persediaan. Persediaan adalah pos-pos aktiva yang dimiliki oleh perusahaan untuk dijual dalam operasi bisnis. Persediaan memerlukan perencanaan, pengelolaan dan pengawasan yang baik agar tidak terjadi kekurangan persediaan, kehilangan, ataupun kesalahan dalam pencatatan jumlah persediaan. Persediaan juga sangat rentan terhadap kerusakan dan pencurian.

Tindakan kecurangan sebenarnya dapat dicegah dengan penerapan Sistem Informasi Akuntansi yang baik. Sistem informasi akuntansi menurut Agustianus Mujilan (2013: 3) menyatakan bahwa: "sangat dibutuhkan dalam mengelola aset pada perusahaan agar aset dapat terjaga dengan baik. Sistem informasi akuntansi merupakan kumpulan sumber daya, seperti manusia, dan peralatan yang diatur untuk mengubah data menjadi informasi. Informasi ini dikomunikasikan kepada beragam pengambilan keputusan. Sistem informasi akuntansi (SIA) mewujudkan perubahan ini secara manual dan terkomputernisasi".

Berdasarkan permasalahan tersebut, peneliti berusaha mencari tahu mengenai sistem informasi akuntansi persediaan pada puskesmas, bagaimana tindakan pencegahan kecurangan pada puskesmas dan apa saja kendala-kendala yang dialami dalam menerapkan Sistem Informasi Akuntansi.

\section{METODE PENELITIAN}

Objek penelitian ini adalah sistem informasi akuntansi persediaan obat dan pencegahan kecurangan. Peneliti melakukan penelitian pada Puskemas di Kecamatan Jampangkulon, Kecamatan
Cibitung dan Kecamatan Surade. Adapun tujuan dilakukannya penelitian ini untuk mengetahui bagaimana sistem informasi akuntansi persediaan obat dalam pencegahan kecurangan di Puskesmas Jampangkulon, Puskesmas Cibitung, Puskesmas Surade dan Puskesmas Buniwangi.

Pada penelitian ini, peneliti menggunakan metode kualitatif dengan pendekatan deskriptif dengan menggunakan permasalahan yang ada. Data yang digunakan dalam penelitian ini adalah data primer dan sekunder. Dengan melakukan observasi dan wawancara kepada pihak-pihak yang dianggap bisa memberikan data. Teknik analisis data yang digunakan yaitu analisis sebelum dilapangan dan analisis selama dan setelah dilapangan.

\section{HASIL DAN PEMBAHASAN}

\section{Gambaran Umum Program Bangkit Usaha Mandiri Sukabumi (BUMI)}

Unit pelaksana teknis puskesmas yang selanjutnya disingkat menjadi UPT Puskesmas adalah UPT pada Dinas Kesehatan Daerah yang selanjutnya disingkat UPTD puskesmas. UPTD Puskesmas merupakan kesatuan organisasi kesehatan fungsional yang merupakan pusat pengembangan kesehatan masyarakat yang juga membina peran serta masyarkat disamping memberikan pelayanan secara menyeluruh dan terpadu kepada masyarakat diwilayah kerjanya dalam bentuk kegiatan pokok.

Wilayah kerja Puskesmas meliputi satu kecamatan atau sebagian dari kecamatan. Faktor kepadatan penduduk, luas daerah, keadaan geografik, dan keadaan infrastruktur lainnya merupakan bahan pertimbangan dalam menentukan wilayah kerja Puskesmas. UPTD Puskesmas sebagai badan layanan kesehatan masyarakat yang memiliki kedudukan secara administratif dan kedudukan dalam hirarki pelayanan kesehataan. Kedudukan secara administratif yang berarti UPTD Puskesmas merupakan perangkat pemerintah daerah Kabupaten yang bertanggung jawab langsung baik secara teknis maupun administratif kepada Kepala Dinas Kesehatan Kabupaten. Kedudukan dalam hirarki pelayanan kesehatan yang berarti UPTD Puskesmas berkedudukan pada tingkat fasilitas pelayanan kesehatan pertamaa sesuai dengan SKN. 


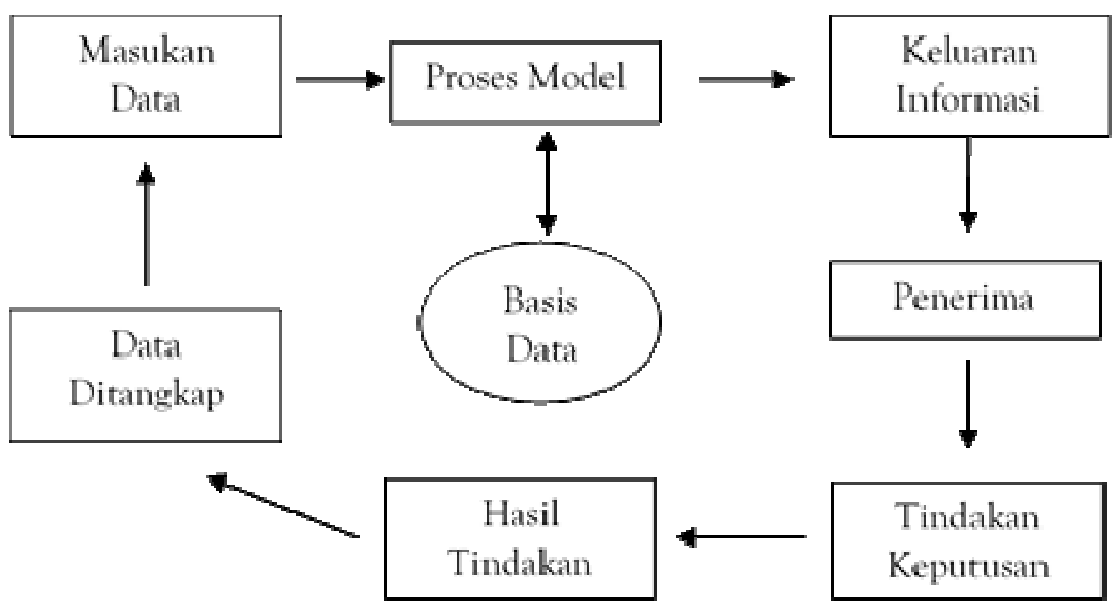

Gambar 1. Sistem Infromasi AKuntansi Pada Puskesmas

Sistem Infomasi Akuntansi Puskesmas Jampang-kulon

Hasil penelitian yang telah dilakukan oleh peneliti pada puskesmas jampangkulon menyatakan bahwa belum menerapkan sistem informasi akuntansi pada persedian obat karena belum ada secara kedinasan. Pihak puskesmas memiliki sistem yang mengatur keberlangsungan kegiatan puskesmas, tetapi untuk sistem informasi akuntansi pihak puskesmas belum menerapkan.

Tahap prosedur persediaan obat puskesmas memiliki 2 prosedur yaitu ada obat umum dan obat JKN/BPJS. Dalam prosedur persediaan obat umum petugas pengelola obat membuat RKO (rencana kebutuhan obat) untuk tahun berikutnya yang diambil dari pola konsumsi penggunaan obat tahun sebelumnya. Setelah RKO dibuatkan kemudian di ajukan ke pimpinan puskesmas, setelah disetujui oleh pimpinan puskesmas RKO tersebut diajukan ke dinas. Setelah dinas menyetujui anggaran tersebut langsung dikirim jadwal pengiriman obat pada puskesmas selama $6 x$ setahun ( 2 bulan sekali). Dalam pengadaan obat JKN setelah disetujui anggaran dilaksanakan $1 \mathrm{x}$ dalam setahun mengikuti regulasi/ tata cara yang telah diterapkan oleh dinas kesehatan. Pencatatan dalam prosedur pengadaan obat dilakukan secara manual. Dalam Pemesanan obat terdapat beberapa bagian yang terlibat diantaranya, pengelola gudang farmasi, dokter, bidan, penyedia anggaran dan kepala puskesmas. Karena dalam pemesanan obat, obat yang digunakan dan dibutukan oleh dokter dan bidan berbeda kebutuhan obatnya maka dirundingkan dengan dokter dan bidan terlebih dahulu. Pada saat obat dikirim dari gudang farmasi ke puskesmas obat umum rutin di antar 2 bulan sekali oleh petugas gudang farmasi Dinas dengan menyertakan bukti mutasi barang kemudian diperiksa pada saat penerimaan obat. Dalam penerimaan obat JKN obat akan dikirimkan beserta faktur penjualan. Dalam prosedur pengeluaran obat, puskesmas mempunyai pustu (puskesmas pembantu) yang mendapat pendistribusian obat dari puskesmas yang terjadwal dalam 1 bulan sekali, yang di sertai SBBK (surat bukti barang keluar). Sedangkan obat yang keluar dari loket harus berdasarkan resep.

Sistem Informasi Akuntansi pada Puskesmas Cibitung Pada puskesmas cibitung pihak puskesmas telah menjalankan sistem informasi akuntansi pada persediaan obat, karena sudah menjadi keharusan bahwa sebuah organissi mempunyai sistem yang mengatur keberlansungan kegiatan puskesmas. Pengadaan obat yang menjadi persediaan obat pada puskesmas, puskesmas memang miliki prosedur yang sama yaitu membuat RKO (rencana kebutuhan obat) yang dilihat dari pola konsumsi pengguaan obat tahun sebelumnya. Sistem pencatatn persediaan obat masih dilakukan secara manual dan komputer. Pada tahap pemesanan obat divisi yang terlibat yaitu pengelola obat, bidan, dokter, pemegang progrm, bendahara, dan kepala puskesmas. Setelah pembuatan RKO kemudian diajukan ke dinas, dinas akan mengirinka jadwal pengiriman obat. Pada saat obat datang dari gdang farmasi dinas obat kemuian di cek jumlahnya sesuai dengan permintaan atau tidak kemudian langsung diterima oleh pengelola obat dan langsung dimasukan ke gudang farmasi puskesmas. Prosedur pengeluaran obat yang diterapkan pada puskesmas Cibitung harus berdasarkan resep.

\section{Sistem Informasi Akuntansi Puskesmas Surade}

Puskesmas surade sudah menerapkan sistem informasi akuntansi karena pihak puskesmas menyadari bahwa segala kegiatan yang berlngsung diatur oleh sistem, agar kegiatan puskesmas 
berjalan dengan lancar, apalagi sistem yang diterapkan berjalan dengan baik.

Prosedur persediaan obat yang diterapakan pada puskesmas ada dua, yaitu obat umum dan obat JKN. Obat umum merupakan obat yang dikirim dari dinas, prosedur permintaan obat umum yaitu pihak puskesmas terutama pengelola obat membuat RKO untuk diajukan ke dinas. Sedangkan prosedur permintaan obat JKN dirancang oleh pengelola obat kemudian membeli sendiri dari e katalog dan dibayar non tunai. Pencatatan persediaan obat yang dilakukan oleh puskesmas yaitu dilakukan secara manual dan kemudian masukan ke komputer. Dalam pemesanan obat pihak puskesmas memiliki tim audit yang terdiri dari berbagaai profesi yang ada di puskesmas, diantaranya ada pihak pelayanan umum, KIA, IGD, dan laboratorium. Dimana dari setiap divisi itu ada satu oran yng membuat rancangaan kebutuhan obat. Seperti dalam pemesanan obat ada obat umum dan obar JKN, dalam penerimaan obat juga ada dua prosedur. Pada peneriman obat umum pihak gudang farmasi mengirmkan obat yang sesuai dengan jadwal pada saat RKO di setujui oleh pihak dinas. Obat yang dikirim langsung diterima dan di cek oleh pengelola obat di puskesmas kemudian disimpan di gudang. Sedangkan penerimaan obat JKN, karena pihak puskesmas membeli sendiri melalui e-katalog kemudiaan di setujui dan obat langsung dikirim ke puskesmas kemudian diterima dan di simpan di gudang. Prosedur pengeluaran obat pada puskesmas harus berdasarkan resep.

\section{Sistem Informasi Akuntansi pada Puskesmas Buniwangi}

Pada puskesmas buniwangi sudah menerapkan sistem informasi akuntansi, karena pihak puskesmas menyadari bahwa setiap organisasi harus puny sistem yang keberlangsungan kegiatan operasinya. Oleh karena itu puskesmas buniwangi menerapkan sitem informasi akuntansi agar kegiatan operasional pada puskesmas berjalan dengan baik.

Prosedur persediaan obat pada puskesmas buniwangi yaitu ada dua jenis obat yaitu obat umum dan obat JKN. Sistem pencatatan yang digunakan pada puskesmas buniwangi masih bersifat manual kemudian di masukan ke komputer untuk membuat laporan. Divisi yang terlibat dalam pemesanan obat yaitu bagian gudang farmasi, dokter, bidan, bendahara, dan kepala puskesmas. Pada saat penerimaan obat dari dinas, obat langsung di cek kemuian diterima dan langsung dimasukan ke dalam gudang farmasi puskesmas. Setiap obat yang keluar dari puskesmas harus berdasarkan resep.

\section{Pencegahan Kecurangan}

Pencegahan Kecurangan pada Puskesmas Jampangkulon

Pencegahan kecurangan yang dilakukan pihak puskesmas jampangkulon pada persediaan obat bahwa setiap obat yang keluar harus berdasarkan resep dan setiap dan dilakukan monitoring. Kemudian pemasukan dan pengeluaran obat harus berdasarkan dokumen. Dengan begitu apaabila ada tindakan menyimpang akan langsung diketahui. Apabila ada kaaryawan yang melakukan kecurangan maka akan langsung dilaporkan kepada kepalaa puskesmas. Untuk meminimalisir tindakan kecurangan yang diakibatkan oleh adanya kesempatan pihak puskesmas melakukan administrasi dengan tertib.

Apabila ada karyawan yang melakukan kecurangan, yaitu dengan mencuri obat pihak pengelola obat akan melaporkan kepada kepala puskesmas. Pihak puskesmas menyadari bahwa tindak kecurangan terjadi karena adanya kesempatan, dengan demikian untuk meminimalisir kesempatan untuk melakukan kecurangan pihak puskesmas memiliki tindakan yaitu dengan melakukan tertib administrasi.

\section{Pencegahan Kecurangan Pada Puskesmas Cibitung}

Tindakan pencegahan yang diterapkan oleh pihak puskesmas cibitung yaitu dengan melakukan monitoring pada setiap bagian yang ada di puskesmas. Pihak puskesmas cibitung menerapkan aturan bahwa setiap karyawan yang menbutuhkaan obat harus diresepkan terlebih dahulu. Apabila ada karyawan yang melakukan kecurangan pihak puskesmas akan menegurnya. Untuk meminimalisir tindakan kecurangan yang diakibatkan oleh adanya kesempatan pihak puskesmas cibitung menerapkan sikap yang bertanggung jawab akan tugas masingmasing.

\section{Pencegahan Kecurangan Pada Puskesmas Surade}

Tindakan pencegahan kecurangan yang diterapakan pada puskesmas surade yaitu dengan pembekalan akhlak yang rutin dilakukan setiap seminggu sekali. Kemudian ada buku bantu yang bisa disandingkan dengan resep yang keluar, pihak puskesmas juga memiliki regulasi pengobatan rasional, dimana pasien hanya dapat menerima 3 jenis obat untuk mencegah penggunaan obat yang berlebihan. Ketika ada karyawan yang melakukan kecurangan pihak puskesmas akan memberika peringatan lisan, apabila masih seperti itu kemudian di beri surat peringatan 1,2, dan 3. Apabila masih 
tetap seperti itu pihak puskesmas mengembalikan karyawan tersebut kepada dinas dengan alasan ketidakpuasan. Puskesmas surade mengadakan apel setiap pagi dimana kegiatan tersebut untuk meningkatkan kedisiplianan dan mengingatkan akan tugas dan tangung jawab masing-masing.

Pencegahan Kecurangan Pada Puskesmas Buniwangi Hal yang paling mendasar dalam pencegahan kecurangan adalah pada saat perencanaan dan dalam pengadaan obat. Cara untuk mencegah kecurangan pada saat obat masuk ke gudang farmasi yaitu dennga danya baper stock, yang disesuaikan dengan oat yang keluar. Apabila ada karyawan yang melakukan kecurangan pihak puskesmas akan melakukan tindakan sesuai prosedur yaitu melakukan teguran, kemudian surat peringatan 1, 2, da 3. Setelah itu langsung dilaporkan kepada dinas. Untuk meminimalisir tindakan kecurangan yang diakibatkan oleh adanya kesemptan pihak puskesmas harus melakukan tertib administrasi, dan melihat dari catatan harian dan bulanan.

\section{Peran Sistem Informasi Akuntansi Dalam} Pencegahan Kecurangan

Peran Sistem Informasi Akuntansi dalam Pencegahan Kecurangan Pada Puskesmas Jampangkulon

Puskesmas jampangkulon belum menerapkan sistem informasi akuntansi pada persediaan obat karena belum ada secara kedinasan. Apabila pihk puskesmas menerapkan sistem informasi akuntansi pada persediaan obat maka akan mempermudah kinerja dan mencegah terjadinya tindakan kecurangan. Apabila sistem yang ada di puskesmas jampangkulon berjalan dengan lancar daan baik makaa akan mencegah terjadinya kecurangan yang bisa saja dilakukan oleh karyawan.

Peran Sistem Informasi Akuntansi dalam Pencegahan Kecurangan Pada Puskesmas Cibitung

Puskesmas cibitung sudah menerapkan sistem informasi akuntansi, dengan diterapkan sistem ini maka kegiatan puskesmas akan berjalan sesuai sistem yang telah diterapkan. Dengan meneerapkan sistem informasi akuntansi pada persediaan obat maka obat akan terkelola dengan baik karena sistem informasi akuntansi sangat dibutukan dalam mengelola aset pada perusahaan.
Peran Sistem Informasi Akuntansi dalam Pencegahan Kecurangan Pada Puskesmas Surade

Puskesmas surade telah menerapkaan sistem informasi akuntansi dalam persediaan obat, karena puskesmas surade menyadari bahwa persediaan obat merupakan salah satu aset yang dimiliki oleh puskesmas. Aset yang harus dijaga untuk keberlangsungan kegiatan operasional puskesmas. Dengan menerapkan sistem informasi akuntansi pada persediaan maka persedian dapat dikelola dengan baik.

Peran Sistem Informasi Akuntansi dalam Pencegahan Kecurangan Pada Puskesmas Buniwangi

Sistem informasi akuntansi sangat dibutuhkan dalam mengelola persediaan, karena persediaan merupakan aset perusahaan yang harus dijaga dan dikeloal dengan baik. Puskesmas buniwangi sudah menerapkan sistem informasi akuntansi pada persediaan obat karena puskesmas bunwangi menyadari bahwa persediaan obat merupakan aset yng dimiliki oleh puskesmas.

Peran sistem informasi akuntansi dalam pencegahan kecurangan sangat efektif karena dengan diterapkan sistem ini maka persediaan yang ada di puskesmas dapat di kelola dengan baik dan lancar. Ketika sistem ini berjalan dengan baik maka kegiatan kecurangan dapat secara langsung terdeteksi.

\section{Kendala Dalam Menerapkan Sistem Informasi Akuntansi}

Menerapkan sistem pasti ada kendala yang dihadapi oleh pihak puskesmas, seperti yang di ungkapkaan oleh Romney \& Steinbart (2017: 11) bahwa "sistem informasi akuntansi memiliki 6 komponen yaitu : Orang yang menggunakan sistem, Prosedur dan intruksi yang digunakan untuk mengumpulkan, memproses dn menyimpan data, Data mengenai organisasi dan aktivitas bisnisnya, Perangkat lunak yang digunakan untuk mengolah data, Infrastruktur teknologi informasi, meliputi komputer, perangkat periperal, dan perangkat jaringan, dan Pengendalian internal dan pengukuraan keamanan yang menyimpan data sistem informasi akuntansi.

Kendala dalam menerapakan Sistem Informasi Akuntansi pada Puskesmas Jampangkulon

Hasil penelitian yang telah dilakukan pada puskesmas jampangkulon bahwa puskesmas jampangkulon belum menerapakan sistem informasi akuntansi pada persedian obat karena 
belum ada secara kedinasan, selain itu juga puskesmas mempunyai kendala yaitu dalam sarana prasarana dan sumber daya manusia yang menunjang diterapkannya sistem ini, pihak puskesmas juga memiliki orang-orang yang handal dalam menggunakan komputer namun masih kurang. Seperti disebutkan diatas apabalia 5 komponen itu belum terpenuhi maka suatu sistem tidak bisa berjalan dengan baik.

Kendala dalam menerapaka Sistem Informasi Akuntansi pada Puskesmas Cibitung

Pihak puskesmas tidak menemukan kendala yang sangat berat, karena secara admin pihak puskesmas sudah terbisa dalam mengatur persediaan obat. Apabila 5 komponenen diat sudah terpenuhi maka sistem yang telah di terapakan di puskesmas cibitung sudah berjalan dengan baik, dengan begitu persediaan obat akan terjaga dan dikelola dengan baik apabila orang yang mengaturnya memahami dan mengerti akan sistem yang sudah dijalankan. Puskesmas Cibitung juga memiliki karyawan yang ahli menggunkan komputer tetapi masih kurang dan masih menginduk ke kepagawaian.

Kendala dalam menerapaka Sistem Informasi Akuntansi pada Puskesmas Surade

Sistem informasi akuntansi pada puskesmas surade sudah diterapkan. Meskipun pada saat awal diterapkannya pihak puskesmas mempunyai kendala yaitu kurangnya sumber daya manusia dan sarana prasarana yang menunjang kegiatan ini, kemudian juga ketika baru diterapkan ada beberapa karyawan yang masih kesulitan dalam menggunakan komputer. Pihak puskesmas surade mengadakan pelatihan yang diadakan puskesmas untuk meningkatkan kualitas karyawan puskesmas surade.

Kendala dalam menerapakan Sistem Informasi Akuntansi pada Puskesmas Buniwangi

Sistem informasi akuntansi pada puskesmas surade sudah diterapkan. Meskipun pada saat awal diterapkannya pihak puskesmas mempunyai kendala yaitu kurangnya sumber daya manusia dan sarana prasarana yang menunjang kegiatan ini, kemudian juga ketika baru diterapkan ada beberapa karyawan yang masih kesulitan dalam menggunakan komputer. Pihak puskesmas surade mengadakan pelatihan yng diadakan puskesmas untuk mrningkatkan kualitas karyawan puskesmas surade. Puskesmas buniwangi memiliki satu karyawan yang sangat mahir dalam menggunakan komputer.

\section{SIMPULAN}

Dari hasil penelitian yang telah dilakukian bahwa tiga dari empat Puskesmas sudah menerapkan sistem informasi akuntansi pada persediaan obat. Sedangkan satu Puskesmas menyatakan belum menerapkan sistem informasi akuntansi karean belum ada secara kedinasan. Pencegahan kecurangan yang dilakukan pada setiap puskesmas berbeda-beda, tetapi cara yang sesuai dengan aturan yang sudah ada yaitu dengan melakukan monitoring. Kemudian apabilia ada karyawan yang melakukan kecurangan pihak puskesmas melakukan teguran lisan kemudian memberikan peringatan, apabila kecurangan tersebut masih dilakukan maka pihak puskesmas melaporkan langsung kepada Dinas atas ketidakpuasan kinerja karyawan tersebut.

Peran sistem informasi akuntansi dalam pencegahan kecurangan sangat efektif karena dengan diterapkannya sistem ini maka persediaan yang ada pada puskesmas dapa dikelola dengan baik. Kendala yang dialami oleh ke empat puskesmas hampir sama yaitu kurangnya sumber daya manusia dan sarana prasarana. Meskipun pihak puskesmas memiliki karyawan yang handal dalam menggunakan komputer tetapi jumlahnya masih kurang.

\section{DAFTAR PUSTAKA}

2014, Pengelolaan Obat Puskesmas, tersedia :

2017. pengertian kecurangan fraud, sudut hukum, tersedia: http//www.suduthukum.com

2017. teori konsep persediaan teori, tersedia: http//www.materi pelajar.com

Baridwan, Zaki. 2015. Intermediate Accounting. Edisi Kedelapan. Yogyakarta: BPFE Yogyakarta.

Djajun, Juhara.2104. Pengaruh sistem informasi akuntansi persedian barang terhadap pengendalian intern persediaan barang pad CV.Tri Multi Manunggal Bandung.

Gelinas, Ulrich, \& Dull, B. Richard, (2012). Accounting Information Systems. Boston: Pwskent Publishing Company.

Gudang Dinkes. [Aceh.tribunnews].

Hans Kartikahadi., dkk. 2016. Akuntansi Keuangan Berdasarkan SAK Berbasis IFRS Buku 1. Jakarta : Salemba Empat

Hiererra, S. E., Efrizon, E., Yun, Y., \& Yuliany, E. (2012). Evaluasi Sistem Informasi Akuntansi Pembelian dan Persediaan Bahan Baku pada PT Sumber Bahagia Metalindo. ComTech: Computer, Mathematics and Engineering Applications, 3(1), 149-153. 
http//www.artikelfarmasi.com

Ikatan Akuntan Indonesia. 2012. Standar Akuntansi Keuangan.Jakarta : Salemba Empat

Ikatan Akuntan Indonesia.2013. Standar Akuntansi Keuangan Entitas Tanpa Akuntanbilitas Publik (SAK ETAP). Jakarta: Ikatan Akuntan Indonesia.

Khomarudin, A. K. (2018). Analisis Sistem Informasi Akuntansi Pengendalian Intern Terhadap Persediaan Bahan Baku PT. Profilindah Kharisma. PRIVE: Jurnal Riset Akuntansi dan Keuangan, 1(2), 89-97.

Krismiaji.2015. Sistem informasi akuntansi, edisi ke empat. Penerbit: unit penerbit dan percetakan sekolah tinggi ilmu manajemen YKPM.

Marfuah, M. (2019). Financial Risk, Good Corporate Governance dan Praktik Perataan Laba di Indonesia. Jati: Jurnal Akuntansi Terapan Indonesia, 2(1), 124-133.

Mufidah, M. (2017). Pengaruh Pengendalian Internal Persediaan dan Sistem Informasi Akuntansi terhadap Upaya Pencegahan Kecurangan (Fraud) dalam Pengelolaan Persediaan pada PT Mitra Jambi Pratama. Jurnal Ilmiah Universitas Batanghari Jambi, 17(3), 103-119.

Mujilan. Agustianus.2012. sistem informasi akuntansi, edisi 1 penerbit wima pers madium

Mulyadi. 2016. Sistem Informasi Akuntansi. Jakarta:

Salemba Empat.

Purwoko, P. (2010). Perancangan Sistem Informasi Akuntansi Pembelian dan Persediaan. CommIT (Communication and Information Technology) Journal, 4(1), 68-76.

Ramadhany, I., Indrawati, N., \& Al Azhar, L. (2017). Pengaruh Sistem Pengendalian Intern, Asimetri Informasi, Kesesuaian Kompensasi Dan Implementasi Good Corporate Governance Terhadap Kecenderungan Kecurangan Akuntansi (Studi Empiris Pada Rumah Sakit Swasta Yang Ada Di Pekanbaru). Jurnal Online Mahasiswa Fakultas Ekonomi Universitas Riau, 4(1), 1253-1267

Rangkuti.2007. Manajemen Persediaan: Aplikasi dibidang Bisnis. Edisi 2. Jakarta : PT. Raja Grafindo Persada.

Romney, M B dn Steinbart P.J.2015. sistem informasi akuntansi .edisi 13.penerbit salemba empat.

Romney, M. B., \& Steinbart, P. J. 2014. Sistem Informasi Akuntansi. Jakarta: Salemba Empat.

Romney,Marshal dan Paul John Steinbart. Sistem informasi akuntansi. Edisi 9. Penerbit: salemba empat.

Rudianto. 2012. Akuntansi Pengantar.Jakarta. Penerbit: Erlangga.

Salim, J., \& Wijaya, T. ANALISIS SISTEM INFORMASI AKUNTANSI PERSEDIAAN BARANG DAGANG PADA PT. AUTOCHEM INDUSTRY CAB. PALEMBANG.

Soemarso, 2014, Akuntansi Suatu Pengantar _ Edisi 5, Jakarta: Salemba Empat.

Sugiyono.2017. metode penelitian, cetakan ke 25 . Bandung: Alfabeta
Sujarweni, V. Wiratna. 2016. Pengantar Akuntansi. Yogyakarta: Pustaka Baru press

Sukirman, S., \& Sari, M. P. (2013). Model deteksi kecurangan berbasis fraud triangle. Jurnal Akuntansi Dan Auditing, 9(2), 199-225.

Sumarson, Thomas.2013. Perpajakan Indonesia (Vol.3). Jakarta: PT. Indeks

Suryanto, S., Gondodiyoto, S., Ristianto, R., Herny, H., \& Nathalia, D. (2009). Evaluasi Sistem Informasi Persediaan pada PT Sumber Mandiri. CommIT (Communication and Information Technology) Journal, 3(1), 50-52

Susanto, Azhar.2017.Sistem akuntansi.Bandung.Lingga Jaya.
Informasi 